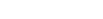

*For correspondence: charlotte@ddm.health

Competing interest: See page 9

Received: 09 August 2021

Accepted: 21 September 2021

Published: 15 December 2021

()This article is Open Access: CC BY license (https://creativecommons.org/licenses/by/4.0/)

Author Keywords: Diabetes mellitus, type 2, Health promotion, Primary health care, Diet, carbohydrate-restricted , Feasibility study, General practice, prediabetes

Copyright (C) 2021, The Authors; DOI:10.3399/BJGPO.2021.0137

\section{The Low Carb Program for people with type 2 diabetes and pre-diabetes: a mixed methods feasibility study of signposting from general practice}

\author{
Emma Scott ${ }^{1}$, Mishkat Shehata ${ }^{1}$, Arjun Panesar ${ }^{2}$, Charlotte Summers ${ }^{2 \star}$, \\ Jeremy Dale ${ }^{1}$
}

\author{
${ }^{1}$ Warwick Medical School, Coventry, UK; ${ }^{2}$ DDM Health, Coventry, UK
}

\begin{abstract}
Background: Evidence shows type 2 diabetes mellitus (T2DM) can be effectively treated with a reduced-carbohydrate diet to support weight loss. Digital apps are increasingly used to support weight loss, yet little is known about their use as part of general practice diabetes care.
\end{abstract}

Aim: Determine the feasibility of signposting from routine NHS general practice to a digital weight management tool (Low Carb Program) for patients with T2DM and pre-diabetes.

Design \& setting: Mixed-methods feasibility study implemented within routine general practice consultations at four practices in the Midlands, England.

Method: General practices offered signposting to eligible patients attending consultations of any type during a 4-week recruitment period. Rates of offering and accepting signposting were recorded, with program registration, program completion, and self-reported health outcomes (weight, haemoglobin A1C $[\mathrm{HbA1} \mathrm{c}])$.

Results: Signposting was offered to 351 patients; 160 (45.6\%) accepted, 103 (29.3\%) registered with the intervention and 43 (26.9\% of patients accepting signposting) completed the programme. GPs reported that signposting added between 1-4 minutes to the consultation length. Patients completing the programme reported greater weight loss $(7.2 \mathrm{~kg}$ versus $1.6 \mathrm{~kg}, P<0.001)$ and $\mathrm{HbA} 1 \mathrm{c}$ improvements $(-9.1 \mathrm{mmol} / \mathrm{mol}$ versus $1.7 \mathrm{mmol} / \mathrm{mol}, P<0.001)$ compared to those who did not, and were more likely to reduce the number of prescribed diabetes medications in general practice.

Conclusions: Signposting from real-world general practice to the Low Carb Program is feasible and can potentially improve diabetes outcomes. Further research should explore whether the process of signposting can be enhanced to increase registration, identify whether additional practice-led support leads to increased programme completion, and confirm the intervention's clinical and cost-effectiveness.

\section{How this fits in}

The feasibility of signposting patients with T2DM to digital health interventions from primary care services has not been extensively examined. This research demonstrates the feasibility of referring patients with T2DM from primary care consultations to digital services that support weight loss. It provides insight into how signposting can benefit patients, and supports the need for more in-depth research to establish the cost and clinical effectiveness of such signposting.

\section{Introduction}

T2DM affects approximately 4.2 million adults in the UK. ${ }^{1}$ Obesity is the primary risk factor for the onset and progression of T2DM, and $80 \%$ of people with T2DM are overweight or obese. ${ }^{2,3}$ Effective, 
accessible, and scalable weight management approaches that can be delivered as part of routine primary care are urgently needed.

Obesity is an important risk factor. Losing weight provides significant health benefits and losing excess body weight contributes to reduction in the risk of T2DM, heart disease, and sleep apnoea. ${ }^{4,5}$

The benefits of a low-carbohydrate diet $(<130 \mathrm{~g}$ carbohydrate per day) in weight management are increasingly recognised. Recent meta-analyses comparing low-carbohydrate and low-fat diets found a significantly greater reduction in body weight for the low-carbohydrate group., ${ }^{3,6} \mathrm{~A}$ recent systematic review and meta-analysis of research evaluating low-carbohydrate diets $(<130 \mathrm{~g} / \mathrm{day}$ or $<26 \%$ of a $2000 \mathrm{kcal} /$ day diet) and very low-carbohydrate diets ( $<10 \%$ calories from carbohydrates) for at least 12-weeks in adults with T2DM reported moderate-to-low certainty evidence that patients adhering to a low-carbohydrate diet for 6 months may experience T2DM remission without adverse consequences. ${ }^{7-9}$

Integrating digital technology into primary care has the potential to increase care access, improve patient outcomes, and reduce costs. Smartphone apps may augment the reach of health services through remote self-management and behavioural change. ${ }^{10}$ The challenge is how to facilitate signposting patients to these digital health tools in a time-efficient manner that does not increase the burden on already stretched primary care services. Scalable access to the resources that educate and support patients with pre-diabetes and T2DM to make long-term dietary changes are needed. Digital weight management interventions are available, but adoption and engagement varies. ${ }^{11-15}$

\section{Objective}

The study's aim was to determine the feasibility of signposting patients with T2DM and pre-diabetes during routine NHS general practice consultations to the 'Low Carb Program', a digital weight management app.

Specific objectives included determining healthcare professionals' ( $\left.\mathrm{HCPs}^{\prime}\right)$ willingness to opportunistically signpost patients; acceptance of signposting and app registration rates; intervention uptake and participant retention; and exploring experiences of intervention use with surveys and interviews.

Table 1 'Low Carb Program' syllabus

\begin{tabular}{|c|c|c|}
\hline Week & Topic & Objective \\
\hline 1 & $\begin{array}{l}\text { Welcome to the type } 2 \\
\text { diabetes / pre-diabetes } \\
\text { program }\end{array}$ & $\begin{array}{l}\text { - Safety notes and alerts to medications that require healthcare } \\
\text { professional teams' assistance } \\
\text { - Benefits of a reduced carbohydrate diet for people with type } 2 \\
\text { diabetes } \\
\text { - Benefits of a reduced carbohydrate diet for people with pre-diabetes }\end{array}$ \\
\hline 2 & Type 2 diabetes and diet & $\begin{array}{l}\text { - Factors that affect blood glucose levels } \\
\text { - Encouragement to engage with their healthcare providers }\end{array}$ \\
\hline 3 & Controlling portion sizes & - Introducing visual methods for interpreting portion size \\
\hline$\underline{4}$ & Real versus processed foods & - Identifying and eliminating refined and processed food \\
\hline 5 & Healthy and unhealthy fats & $\begin{array}{l}\text { - Discussion of fat types and making appropriate choices depending } \\
\text { on goals }\end{array}$ \\
\hline 6 & Vegetables & $\begin{array}{l}\text { - Demonstrating the carbohydrate content of vegetables and cooking } \\
\text { methods }\end{array}$ \\
\hline 7 & Fruit & - Reviewing the amount of sugar and starch in fruit and vegetables \\
\hline 8 & Snacks and desserts & - Examining low-carb snack, dessert, and drink options \\
\hline 9 & Drinks & - Tips on alcohol and eating out options \\
\hline 10 & Eating out and takeaways & $\begin{array}{l}\text { - Managing eating on the go and when travelling } \\
\text { - Making healthier takeaway and food choices }\end{array}$ \\
\hline 11 & $\begin{array}{l}\text { Practical ways to eat less } \\
\text { carbohydrates }\end{array}$ & $\begin{array}{l}\text { - Practical tips for reducing carbohydrate intake further } \\
\text { - Safety information - highlighting medications that require healthcare } \\
\text { professional team assistance }\end{array}$ \\
\hline 12 & Timing your meal & $\begin{array}{l}\text { - Introducing the principles of reducing the eating window using the } \\
16: 8 \text { model }\end{array}$ \\
\hline
\end{tabular}




\section{Intervention}

The 'Low Carb Program' is an NHS-approved app that supports people with T2DM and pre-diabetes to make dietary and lifestyle changes to achieve weight loss. It provides evidence-based structured education and goal-focused behaviour change coaching to support weight loss through adoption of a low-carbohydrate diet (130g carbohydrate per day). ${ }^{16}$ Modules unlock weekly over 12-weeks, delivered using videos, ranging from 3-12 minutes, and written content (see Table 1 for syllabus). Participants make behavioural changes based on goals at the end of each module. The app engages the Social Ecological Model of Health ${ }^{17-20}$ and solution-focused coaching, placing the focus on a person's present and future circumstances and goals. Patients are supported with self-monitoring tools ( $\mathrm{HbA} 1 \mathrm{c}$, weight, food diary); and recipes recommended by artificial intelligence to match patients' dietary preferences and based on liked recipes, foods logged in their food diary, and recipes liked by other members who share similar demographics.

\section{Method}

\section{Study design, practice participation, and participant recruitment}

This study was a mixed methods feasibility study with the intervention implemented within routine general practice consultations.

Four general practices were recruited, aiming for diversity in setting and size. Practice staff, including GPs, nurses, and healthcare assistants (HCAs), received: a 10-minute slide presentation about the intervention; a booklet explaining the low-carbohydrate approach and what app use involves; referral cards to enable free patient access; a brief signposting statement to use with eligible patients (Appendix 1); and a deprescribing protocol. ${ }^{21}$ (Appendix 2).

Each practice was asked to implement its own approach to incorporate signposting into the consultation, utilising a signposting statement that drew upon Prospect Theory ${ }^{22}$ and the 'Ask' domain of motivational interviewing ${ }^{23}$ to give a gain-framed message that highlighted the intervention's positive benefits, ${ }^{24}$ and incorporated GP endorsement to encourage uptake. ${ }^{25}$

An electronic pop-up was installed on the practices' patient management system to trigger a signposting prompt when eligible patients presented. It offered various response options: accepted signposting, declined, inappropriate to offer.

Patients aged $\geq 18$ years, with a confirmed diagnosis of T2DM or pre-diabetes and a body mass index $\geq 25 \mathrm{~kg} / \mathrm{m}^{2}$, who presented for any reason during the recruitment window were eligible for signposting if the consulting HCP felt it appropriate. Patients who accepted signposting were given a referral card to gain free access to the intervention. Participant information sheets and digital consent forms were presented on a study-specific 'Low Carb Program' webpage. A 4-week recruitment period was anticipated as sufficient to allow at least 300 patients to be offered signposting.

Practice staff (GPs, nurses, and HCAs) delivering care to patients with T2DM and pre-diabetes on a regular basis at the participating practices were invited to use the signposting resources.

\section{Data collection}

Participating practices provided information on T2DM and pre-diabetes rates and pop-up prompt responses using population report searches, including age, sex, and ethnicity of all participants offered signposting. The 43 ethnic identities for patients with a diagnosis of T2DM were collapsed into five overarching ethnic groups for analysis: White, Asian, Black, Mixed, or unknown/missing. Data were anonymised and non-identifiable.

Self-reported patient registration (age, sex, height, ethnicity, diabetes type, and duration), module completion, and health data were extracted from the intervention. Patients reported their weight, $\mathrm{HbA} 1 \mathrm{c}$, and diabetes medications at baseline and regular 3-monthly intervals.

Behavioural change interventions rarely achieve $100 \%$ adherence. ${ }^{26}$ Participants completing $\geq 75 \%$ $(\geq 9 / 12)$ modules were classified as intervention completers. Participants completing between 2 and 8 modules classified partial completers, and those completing $\leq 1$ modules as non-completers. Retention at 3 and 6 months was defined as providing self-monitoring data at these time points.

Participants registered with the intervention were invited to complete a survey (13 closed questions and three open-text questions) about their experience of the signposting and using the app, 3 and 6 months post-registration. 


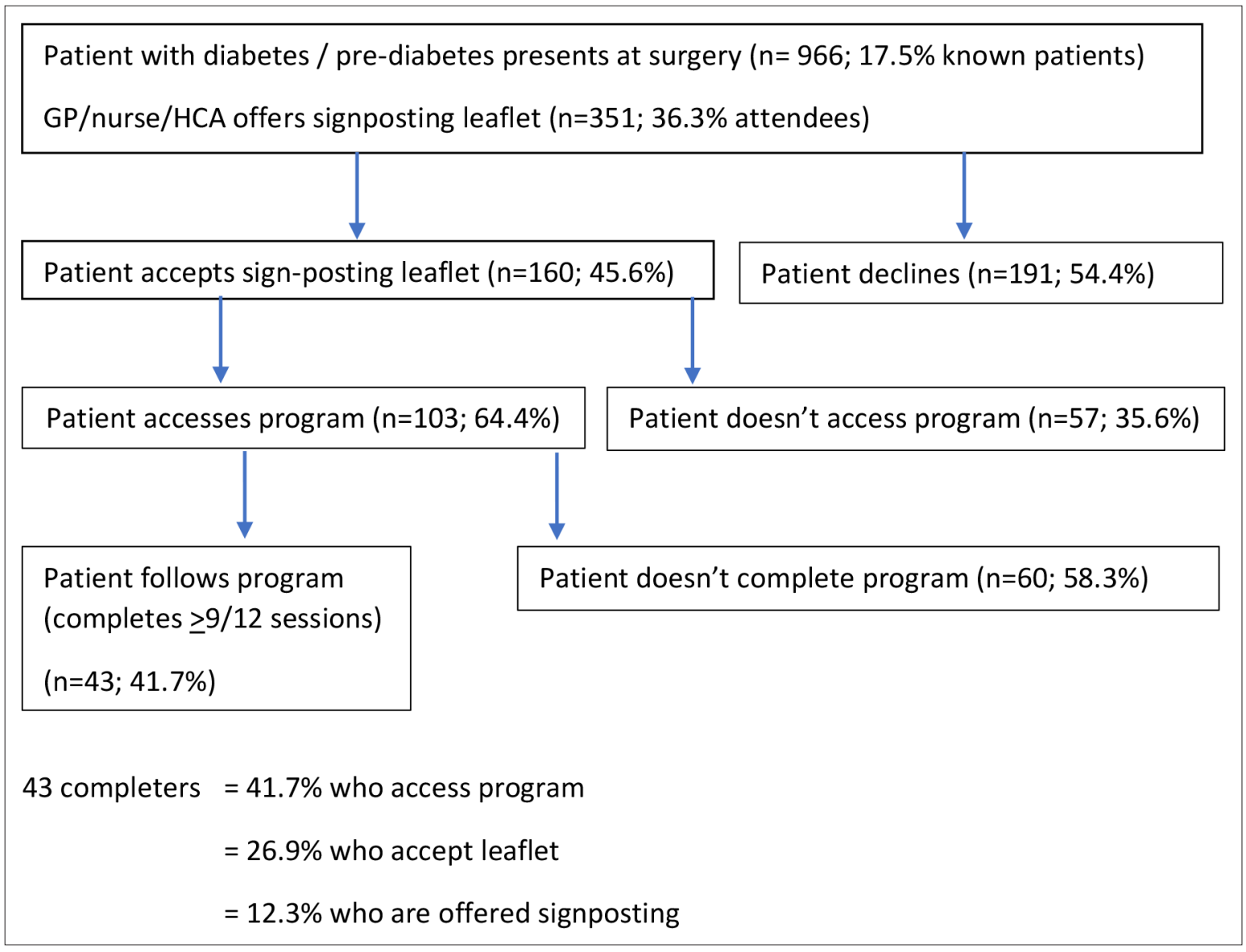

Figure 1 Flow of patients through the study

Practice staff participated in either a one-on-one interview or focus group.

\section{Data analysis}

Quantitative analysis was undertaken using SPSS (version 26). Comparison of patient demographics at different stages of participation was undertaken using 2 and Student $t$-tests. Exploratory outcomes assessments were undertaken using Student $t$-tests, Pearson Correlation Coefficients, and analyses of variance (ANOVAs). Interviews and focus groups were audio-recorded and transcribed verbatim prior to analysis. Framework Analysis ${ }^{27}$ of the data was undertaken using a framework developed from the interview questions.

\section{Results}

\section{Recruitment and retention}

Participating practices covered a total population of 65 118, ranging in size from 8200 to 26500 patients, in urban, suburban, and rural communities. Mean T2DM incidence rate across the practices

Table 2 Signposting acceptance rates by practice

\begin{tabular}{|c|c|c|c|c|c|}
\hline & Practice A & Practice B & Practice C & Practice D & Total \\
\hline Eligible patients during 4 week recruitment period & 141 & 585 & 63 & 177 & 966 \\
\hline Offered signposting & $60(42.6 \%)$ & $190(32.5 \%)$ & $63(100 \%)$ & $38(21.5 \%)$ & $351(36.3 \%)$ \\
\hline Accepted signposting & $39(65.0 \%)^{a}$ & $89(46.8 \%)$ & $24(38.1 \%)$ & $8(21.1 \%)^{b}$ & $160(45.6 \%)$ \\
\hline
\end{tabular}

Significant difference in acceptance rate by practice $\left(\chi^{2}=19.9 ; P<0.001\right)$. ${ }^{\text {Higher }}$ than expected. ${ }^{\text {b }}$ Lower than expected. 
Table 3 Patient demographics

\begin{tabular}{|c|c|c|c|c|}
\hline & Offered signposting & Accepted & Declined & Registered with LCP \\
\hline Mean age, years $( \pm S D)$ & $63.6 \pm 12.8$ & $59.9 \pm 12.3^{a}$ & $66.6 \pm 12.4^{a}$ & $57.5 \pm 12.9$ \\
\hline Sex (male) & $53.3 \%$ & $55.6 \%$ & $51.3 \%$ & $46.6 \%$ \\
\hline \multicolumn{5}{|l|}{ Ethnicity: } \\
\hline White & 106 & 40 & 66 & $75^{b}$ \\
\hline Black & 41 & $28^{a}$ & 13 & 9 \\
\hline Asian & 32 & 14 & 18 & $19^{b}$ \\
\hline Mixed & 83 & 16 & $67^{a}$ & 0 \\
\hline Unknown ${ }^{c}$ & 14 & 7 & 7 & 0 \\
\hline Missing & 75 & 55 & 20 & 0 \\
\hline \multicolumn{5}{|l|}{ Diagnosis: } \\
\hline T2DM & & & & $86(83.5 \%)$ \\
\hline Pre-diabetes & & & & $11(10.7 \%)$ \\
\hline Not stated & & & & $6(5.8 \%)$ \\
\hline \multicolumn{5}{|l|}{ Time since diagnosis: } \\
\hline$<5$ years & & & & $40(38.8 \%)$ \\
\hline $5-10$ years & & & & $36(35.0 \%)$ \\
\hline $11-15$ years & & & & $10(9.7 \%)$ \\
\hline $16-20$ years & & & & $11(10.7 \%)$ \\
\hline$>20$ years & & & & $6(5.8 \%)$ \\
\hline
\end{tabular}

LCP $=$ Low Carb Program.

aSignificant difference between those who accepted and declined the signposting offer $(P<0.05)$.

${ }^{b}$ Number registering appears greater than number accepting, likely due to participants with unknown or missing data in practice self-reporting ethnicity during the registration process.

${ }^{c}$ Coded as unknown on patient management system in practice.

was $4.7 \%$ (range $2.2 \%, 7.2 \%$ of the practice list) and for pre-diabetes $3.7 \%$ (range $1.9 \%, 4.9 \%$ of the practice list).

Figure 1 shows the patient recruitment pathway from signposting to completion of the intervention. Across the practices, 966 eligible patients presented during the 4-week recruitment window; 351 (36.3\%) patients were offered signposting; of which $160(45.6 \%)$ accepted a referral for the app (practice range 21.0-65.0\%) and 103 (29.3\%) registered with the intervention (Table 2).

Forty-three patients $(41.7 \%$ registrants; $26.9 \%$ of patients accepting signposting) completed the intervention ( $\geq 9 / 12$ modules) and 34 (33.0\% of registrants) partially completed the programme (2-8 modules).

\section{Participant characteristics}

There was a difference in signposting acceptance by ethnicity $\left(\chi^{2}=30.64, P<0.001\right)$, with a higher acceptance rate among Black patients (Table 3). After accepting signposting, White patients were more likely to register $\left(\chi^{2}=47.0, P<0.001\right)$.

Patients accepting signposting were younger than patients who declined (mean age 59.9 \pm 12.2 years versus $66.6 \pm 12.4$ years; $t=5.1, P<0.001)$. Similarly, patients who registered with the programme were younger than the overall cohort $(57.5 \pm 13.0$ years versus $64.9 \pm 12.6$ years; $t=5.5, P<0.001)$. There was no sex difference between patients accepting and declining signposting, nor between those who registered and those who were eligible for signposting. 
Table 4 Self-reported outcome measures, by number of Low Carb Program modules completed

\begin{tabular}{|c|c|c|c|c|c|c|c|}
\hline & & \multicolumn{6}{|c|}{ Number of modules completed } \\
\hline & All participants & \multicolumn{2}{|c|}{ 9-12 modules } & \multicolumn{2}{|c|}{ 2-8 modules } & \multicolumn{2}{|c|}{1 or no modules } \\
\hline \multirow[t]{2}{*}{$\mathbf{N}$} & \multirow{2}{*}{$\begin{array}{c}103 \\
\text { Baseline }\end{array}$} & \multicolumn{2}{|c|}{$43(41.7 \%)$} & \multicolumn{2}{|c|}{34 (33\%) } & \multicolumn{2}{|c|}{$26(25.2 \%)$} \\
\hline & & Baseline & Follow up & Baseline & Follow up & Baseline & Follow up \\
\hline Mean weight, kg & $94.4 \pm 19.0$ & $107.3 \pm 19.2^{a}$ & $100.1 \pm 16.8^{b, c}$ & $88.2 \pm 12.4$ & $87.3 \pm 12.3^{b, c}$ & $89.2 \pm 17.4$ & None of these \\
\hline Weight range, $\mathrm{kg}$ & $59.9-156.0$ & $69-156$ & $63-148$ & $59.9-110.0$ & $60.4-109.0$ & $64.0-142.6$ & provided follow \\
\hline $\mathrm{HbA} 1 \mathrm{c}, \mathrm{mmol} / \mathrm{mol}$ & $66.1 \pm 23.4$ & $70.5 \pm 28.2$ & $61.4 \pm 24.0^{b}$ & $65.6 \pm 23.9$ & $63.9 \pm 23.8^{d}$ & $60.3 \pm 10.8$ & $\begin{array}{l}\text { up data for } \\
\text { comparison }\end{array}$ \\
\hline $\mathrm{HbA} 1 \mathrm{c}$ range, $\mathrm{mmol} / \mathrm{mol}$ & $42.1-149.2$ & $44.3-149.2$ & $42.1-129.5$ & $42.1-140.4$ & $42.1-118.6$ & $42.1-82.5$ & \\
\hline $\begin{array}{l}\text { Median number of } \\
\text { medications taken }\end{array}$ & 2 & 2 & $1^{b}$ & 2 & 1 & 2 & \\
\hline $\begin{array}{l}\text { Range number of } \\
\text { medications taken }\end{array}$ & $0-3$ & $0-3$ & $0-3$ & $0-3$ & $0-3$ & $0-3$ & \\
\hline
\end{tabular}

a Significant difference compared to both other groups at baseline $(P<0.05)$. ${ }^{b}$ Significant difference within group from baseline $(P<0.001)$. ${ }^{\mathrm{S}}$ Significant difference between groups at follow up $(P<0.001)$. ${ }^{d}$ Significant difference within group from baseline $(P>0.01)$.

\section{Registration with the intervention}

Of the 103 patients registered, $46.6 \%$ were male, mean age $57.5 \pm 12.9$ years, and $72.8 \%$ White, $18.4 \%$ Asian and $8.7 \%$ black. Eighty-six (83.5\%) had a diagnosis of T2DM, 11 (10.7\%) had pre-diabetes, and six $(5.8 \%)$ identified as obese but did not indicate diabetes diagnosis. Patient T2DM or pre-diabetes diagnosis date ranged from within the last 5 years (38.8\%) to $>20$ years ago (5.8\%; Table 3 ). The mean baseline weight of those who registered was $96.4 \pm 19.0 \mathrm{~kg}$ (Table 4).

Of 103 registrants, 43 (41.7\%) completed the intervention (>9/12 modules), 34 (33.0\%) partially completed the programme (2-8 modules), and the remaining $26(25.2 \%)$ were non-completers.

\section{Outcome data}

Seventy-eight patients $(75.7 \%)$ were retained and provided post-intervention follow-up data at 3-months and $60(58.3 \%)$ at 6-months from baseline. At the most recent data collection $(7.3 \pm 2.9$ months from baseline), mean weight loss was $7.2 \pm 5.0 \mathrm{~kg}$ for completers and $1.6 \pm 1.5 \mathrm{~kg}$ for partial completers $(t=6.1, P<0.001)$.

Fifty-one patients provided follow-up HbA1c data (Table 4), which was a drop from $65.2 \pm 23.4 \mathrm{mmol} /$ $\mathrm{mol}$ at baseline to $62.5 \pm 23.7 \mathrm{mmol} / \mathrm{mol}$ at follow-up $(t=5.6, P<0.001)$. Participants with a higher $\mathrm{HbA} 1 \mathrm{c}$ tended to complete the programme, and for these individuals there was a mean reduction in $\mathrm{HbA} 1 \mathrm{c}$ of $9.1 \mathrm{mmol} / \mathrm{mol}$. Changes in weight and $\mathrm{HbA} 1 \mathrm{c}$ were correlated $(r=0.393, P=0.004)$.

At baseline, patients reported a median of two (range 0-3) prescribed medications for diabetes. Eighteen (41.8\%) completers and seven (20.6\%) partial completers reduced medications.

\section{HCP views}

Nineteen GPs, practice nurses, and HCAs participated in interviews or focus groups prior to initiating signposting. Eleven follow-up interviews were completed post-signposting.

Most were positive about signposting to the intervention using the materials provided and the potential for positive patient outcomes.

Main concerns were lack of time to opportunistically signpost within a 10-minute consultation, the need to tailor signposting to individual patients' requirements, and uncertainty about patient acceptance. Provider-specific barriers included confidence in deprescribing medication and its consequential workload.

They reported that some patients needed additional assistance with registering with the app, but most were happy to proceed independently and liked the app being accessible on-demand. HCPs who were more enthusiastic about promoting lifestyle change reported greater success at signposting patients and had higher acceptance rates. Most felt they would continue to signpost to the intervention. 
The time involved in signposting varied across the practices. Two practices reported signposting added 2-4 minutes to consultations, depending on information requested by patients. One practice offered signposting in a flu clinic and found it was possible to signpost in under a minute. Medication changes, where required, were estimated as adding up to 10 minutes more. More follow-up with patients was required to adjust diabetes management following weight loss. However, the short-term increase in consultation time or frequency was expected to be outweighed by longer-term reduction in appointments as diabetes control improved.

\section{Patient experience}

Nineteen (18.4\%) patients responded to the 3- and 6-month questionnaires. Responders were broadly representative of the participants registered with the programme, although male participants were slightly overrepresented.

Most ( $n=17,89.5 \%$ ) felt that the GP consultation was a good time to be offered the Low Carb Program referral card; all were pleased to have been offered signposting, and most ( $n=18,94.7 \%)$ found it easy to understand what the intervention entailed.

\section{Discussion}

\section{Summary}

This study demonstrates the feasibility of signposting patients with T2DM or pre-diabetes to the Low Carb Program as part of routine general practice care. With a minimal implementation package, and a pragmatic approach to delivery designed to avoid disruption to normal general practice workflows, the study demonstrated rates of signposting acceptability to eligible patients (45.6\%); uptake (accessing the programme; 64.4\%), and adherence (completing the programme; $41.7 \%$ ). Patients who completed $\geq 9$ of the 12 intervention modules reported an average weight loss of $7.2 \mathrm{~kg}$ compared to $1.6 \mathrm{~kg}$ for partial completers. Similarly, patients who completed the programme reduced HbA1c by $9.1 \mathrm{mmol} / \mathrm{mol}(0.83 \%)$ compared to $1.7 \mathrm{mmol} / \mathrm{mol}(0.16 \%)$ for partial completers, and about one third of participants reduced the number of diabetes medications that they were taking.

Primary care teams welcomed their patients gaining free access to the app, appreciated the guidance that they received, and experienced the intervention as adding about 2-4 minutes time to standard care. The practice with the lowest rates for offering signposting also had the lowest rate for patient acceptance; factors that affect the extent to which patients are offered and accept signposting need further consideration. Although the completion of follow-up surveys by patients was low, those who did complete surveys expressed high intervention satisfaction.

\section{Strengths and limitations}

A strength of this study is its pragmatic, real-world design. The protocol allowed practices to implement signposting to the intervention in whichever way worked best within their existing workflows. Through a mixed methods design, data were available from general practice record systems; the Low Carb Program; patient surveys; and HCP interviews and focus groups, which allowed a detailed understanding of the intervention's implementation, use, and effect. Another strength is the recruitment of practices in varied settings with diverse populations, so increasing the generalisability of this study's findings.

Participating HCPs found the implementation materials helpful but there is scope to develop these to support more effective programme signposting and patient follow-up. As a pragmatic study, it was not prescriptive about what GPs should do after signposting, but greater patient follow-up might have encouraged an increased level of intervention registration.

Use of self-reported data is a limitation, although previous research has found that self-reported health outcomes are close to actual values. ${ }^{28,29}$ Although beyond the scope of this feasibility study, future research should extract data on $\mathrm{HbA} 1 \mathrm{c}$, weight, and medications directly from GP record systems rather from than patients' self-report data. It is difficult to rule out the effect of medication on weight and $\mathrm{HbA} 1 \mathrm{c}$ status. Age, sex, ethnicity, and time with diabetes may have been confounding variables. However, analysis of these variables fell outside of the scope of assessing the feasibility of signposting to the intervention in general practice. 
Challenges identified in this study were minimal with most attributable to lack of time. In busy primary care practices, it is difficult to recruit staff to maximise patient recruitment and interview all providers pre- and post-recruitment. Incentivisation should be considered in future research. Another limitation is the signposting statement, which could be made clearer and more inviting. Further research should explore signposting statements that will be more likely to engage potential participants.

Survey responses disproportionately reflected experiences of participants who had completed the programme, hence their enthusiasm should be interpreted cautiously.

\section{Comparison with existing literature}

These findings are comparable with those of similar interventions. HeLP-Diabetes, a web-based tool ${ }^{30}$ reported lower uptake, engagement, and completion rates (9.4\% of those who registered). Evaluation of a UK-based digital lifestyle intervention reported a similar mean weight loss at 6-months: $7.12 \mathrm{~kg}$ $(-7.50 \% \text {; SD 6.37; } P<0.001)^{31}$ compared to $7.2 \pm 5.0 \mathrm{~kg}$ in the present study. A randomised controlled trial evaluating the effectiveness of a digital intervention in Australia found a small improvement in $\mathrm{HbA} 1 \mathrm{c}$ in the intervention arm compared to baseline of similar scale to that observed in the present study. ${ }^{32}$

Based on a 'light-touch' 10-minute presentation to staff and variable usage of materials prompting a 2-4-minute brief intervention, this intervention was able to achieve high patient uptake within the context of primary care. Other interventions typically require staff resources. HeLP-Diabetes used practice staff to identify eligible patients from medical record searches and recruited using consultations and SMS. ${ }^{30}$ Given the feasibility of signposting to the intervention in primary care without burdening staff, it is prudent to research which benefits can be widely replicated.

\section{Implications for research and practice}

The NHS Weight Management Programme is a government initiative launching in the UK in late 2021, with general practice the primary source of patient referrals. ${ }^{33,34}$ The programme will incentivise HCPs to signpost patients with obesity to a digital app following a brief consultation delivered through general practice. The results of this feasibility study are particularly relevant and transferable to this initiative, as there is minimal research on the feasibility of signposting patients to digital apps. These results demonstrate that signposting to a digital app is feasible as part of routine general practice care, and the high signposting rate of demonstrates HCPs' willingness to opportunistically signpost patients without financial incentives.

This study demonstrates the feasibility of signposting patients with T2DM and pre-diabetes to the Low Carb Program. With the implementation of this very brief intervention as part of routine care, about $12 \%$ of eligible patients complete the programme; it also has high acceptability to primary care teams and patients. Further research should test this finding with more practices and patients; refine implementation guidance; and enhance engagement strategies to maximise programme take-up, completion, and patient benefits.

\section{Funding}

This research received no specific grant from any funding agency in the public, commercial or notfor-profit sectors. DDM Health provided free-of-charge access to the Low Carb Program for patients participating in the study. MS participated in this study while an Academic Clinical Fellow, funded by Health Education England.

Ethical approval

NHS Research Ethics and Health Research Authority study approval was obtained. University of Warwick endorsed the study so far as ethics is concerned. Financial support was not provided.

Provenance

Freely submitted; externally peer reviewed.

Acknowledgments

The authors are grateful to the general practices and patients who participated in this study. 


\section{Competing interests}

AP and CS are directors of DDM Health.

\section{References}

1. Diabetes UK. Diabetes prevalence 2019. 2019; https://www.diabetes.org.uk/professionals/position-statementsreports/statistics/diabetes-prevalence-2019 (accessed 2 Dec 2021).

2. Maggio CA, Pi-Sunyer FX. Obesity and type 2 diabetes. Endocrinol Metab Clin North Am 2003; 32(4): 805-822. DOI: https://doi.org/10.1016/S0889-8529(03)00071-9

3. Mansoor N, Vinknes KJ, Veierød MB, Retterstøl K. Effects of low-carbohydrate diets V. low-fat diets on body weight and cardiovascular risk factors: a meta-analysis of randomised controlled trials. Br J Nutr 2016; 115(3): 466-479. DOI: https://doi.org/10.1017/S0007114515004699

4. Tuomilehto J, Lindström J, Eriksson JG, et al. Prevention of type 2 diabetes mellitus by changes in lifestyle among subjects with impaired glucose tolerance. N Engl J Med 2001; 344(18): 1343-1350. DOI: https://doi.org/10.1056/ NEJM200105033441801

5. Rice TB, Foster GD, Sanders MH, et al. The relationship between obstructive sleep apnea and self-reported stroke or coronary heart disease in overweight and obese adults with type 2 diabetes mellitus. Sleep 2012; 35(9): 1293. DOI: https://doi.org/10.5665/sleep.2090

6. Sackner-Bernstein J, Kanter D, Kaul S. Dietary intervention for overweight and obese adults: comparison of lowcarbohydrate and low-fat diets. A meta-analysis. PLoS One 2015; 10(10): e0139817. DOI: https://doi.org/10.1371/ journal.pone.0139817

7. Goldenberg JZ, Day A, Brinkworth GD, et al. Efficacy and safety of low and very low carbohydrate diets for type 2 diabetes remission: systematic review and meta-analysis of published and unpublished randomized trial data. BMJ 2021; 372: m4743. DOI: https://doi.org/10.1136/bmj.m4743

8. Dyson PA, Beatty S, Matthews DR. A low-carbohydrate diet is more effective in reducing body weight than healthy eating in both diabetic and non-diabetic subjects. Diabet Med 2007; 24(12): 1430-1435. DOI: https://doi.org/10. $1111 /$ j.1464-5491.2007.02290.x

9. Saslow LR, Kim S, Daubenmier JJ, et al. A randomized pilot trial of a moderate carbohydrate diet compared to a very low carbohydrate diet in overweight or obese individuals with type 2 diabetes mellitus or prediabetes. PLoS One 2014; 9(4): e91027. DOI: https://doi.org/10.1371/journal.pone.0091027

10. Hoffman $L$, Benedetto $E$, Huang $H$, et al. Augmenting mental health in primary care: a 1-year study of deploying smartphone apps in a multi-site primary care/behavioral health integration program. Front Psychiatry 2019; 10: 94. DOI: https://doi.org/10.3389/fpsyt.2019.00094

11. Kar $P$, Goward $C$, Whitman $M$, et al. Engagement and effectiveness of digitally enabled behavioural change support for people living with type 2 diabetes. Pract Diab 2020; 37(5): 167-172. DOI: https://doi.org/10.1002/pdi. 2295

12. Signal V, McLeod M, Stanley J, et al. A Mobile- and web-based health intervention program for diabetes and prediabetes self-management (BetaMe/Melon): process evaluation following a randomized controlled trial. $J$ Med Internet Res 2020; 22(12): e19150. DOI: https://doi.org/10.2196/19150

13. Hansel B, Giral P, Gambotti L, et al. A fully automated web-based program improves lifestyle habits and $\mathrm{HbA} 1 \mathrm{c}$ in patients with type 2 diabetes and abdominal obesity: randomized trial of patient E-Coaching nutritional support (the anode study. J Med Internet Res 2017; 19(11): e360. DOI: https://doi.org/10.2196/jmir.7947

14. Villinger $\mathrm{K}, \mathrm{Wahl} \mathrm{DR}$, Boeing $\mathrm{H}$, et al. The effectiveness of app-based mobile interventions on nutrition behaviours and nutrition-related health outcomes: a systematic review and meta-analysis. Obes Rev 2019; 20(10): 1465-1484. DOI: https://doi.org/10.1111/obr.12903

15. Saslow LR, Moskowitz JT, Mason AE, et al. Intervention enhancement strategies among adults with type 2 diabetes in a very low-carbohydrate web-based program: evaluating the impact with a randomized trial. JMIR Diabetes 2020; 5(3): e15835. DOI: https://doi.org/10.2196/15835

16. Watanabe $M$, Tozzi R, Risi R, et al. Beneficial effects of the ketogenic diet on nonalcoholic fatty liver disease: a comprehensive review of the literature. Obes Rev 2020; 21(8): e13024. DOI: https://doi.org/10.1111/obr.13024

17. Golden SD, Earp JAL. Social ecological approaches to individuals and their contexts: twenty years of health education \& behavior health promotion interventions. Health Educ Behav 2012; 39(3): 394-372. DOI: https://doi. org/10.1177/1090198111418634

18. Summers C, Curtis K. Novel Digital Architecture of a "Low Carb Program" for Initiating and Maintaining LongTerm Sustainable Health-Promoting Behavior Change in Patients with Type 2 Diabetes. JMIR Diabetes 2020; 5(1): e15030. DOI: https://doi.org/10.2196/15030

19. Panter-Brick $\mathrm{C}$, Clarke SE, Lomas $\mathrm{H}$, et al. Culturally compelling strategies for behaviour change: a social ecology model and case study in malaria prevention. Soc Sci Med 2006; 62(11): 2810-2825. DOI: https://doi.org/10.1016/j. socscimed.2005.10.009

20. Saslow LR, Summers C, Aikens JE, Unwin DJ. Outcomes of a digitally delivered low-carbohydrate type 2 diabetes self-management program: 1-year results of a single-arm longitudinal study. JMIR Diabetes 2018; 3(3): e12. DOI: https://doi.org/10.2196/diabetes.9333

21. Murdoch $C$, Unwin $D$, Cavan $D$, et al. Adapting diabetes medication for low carbohydrate management of type 2 diabetes: a practical guide. Br J Gen Pract 2019; 69(684): 360-361. DOI: https://doi.org/10.3399/bjgp19X704525 
22. Kahneman D, Tversky A. Prospect theory: an analysis of decision under risk. Econometrica 1979; 47(2): $263-91$. DOI: https://doi.org/10.2307/1914185

23. Rollnick S, Butler CC, Kinnersley P, et al. Motivational interviewing. BMJ 2010; 340: c1900: c1900: . DOI: https:// doi.org/10.1136/bmj.c1900

24. Churchill S, Pavey L. Promoting fruit and vegetable consumption: the role of message framing and autonomy. $\mathrm{Br} \mathrm{J}$ Health Psychol 2013; 18(3): 610-622. DOI: https://doi.org/10.1111/bjhp.12007

25. von Wagner C, Hirst Y, Tookey S, et al. Use of a GP-endorsed 12 months' reminder letter to promote uptake of bowel scope screening: protocol for a randomised controlled trial in a hard-to-reach population. BMJ Open 2018; 8(5): e022263. DOI: https://doi.org/10.1136/bmjopen-2018-022263

26. Friedman LM, Furberg CD, DeMets DL, et al. In: Fundamentals of Clinical Trials. Cham: Springer; 2015. DOI: https://doi.org/10.1007/978-3-319-18539-2

27. Ritchie J, Lewis J, et al. Qualitative research practice: A guide for social science students and researchers. London: Sage; 2013

28. McAdams MA, Van Dam RM, Hu FB, . Comparison of self-reported and measured BMI as correlates of disease markers in US adults. Obesity 2007; 15(1): 188-196. DOI: https://doi.org/10.1038/oby.2007.504

29. Løvaas KF, Cooper JG, Sandberg S, et al. Feasibility of using self-reported patient data in a national diabetes register. BMC Health Serv Res 2015; 15(1): 553. DOI: https://doi.org/10.1186/s12913-015-1226-0

30. Poduval S, Marston L, Hamilton F, et al. Feasibility, acceptability, and impact of a web-based structured education program for type 2 diabetes: real-world study. JMIR Diabetes 2020; 5(1): e15744. DOI: https://doi.org/10.2196/ 15744

31. Idris I, Hampton J, Moncrieff F, Whitman M. Effectiveness of a digital lifestyle change program in obese and type 2 diabetes populations: service evaluation of real-world data. JMIR Diabetes 2020; 5(1): e15189. DOI: https://doi. org/10.2196/15189

32. Gong E, Baptista S, Russell A, et al. My diabetes coach, a mobile app-based interactive conversational agent to support type 2 diabetes self-management: randomized effectiveness-implementation trial. J Med Internet Res 2020; 22(11): e20322. DOI: https://doi.org/10.2196/20322

33. Department of Health and Social Care. New specialised support to help those living with obesity to lose weight [4 Mar 2021]. 2021; https://www.gov.uk/government/news/new-specialised-support-to-help-those-living-with-obesityto-lose-weight (accessed 30 Nov 2021).

34. Pulse. New digital weight management service opens to GP referrals [online]. 1 July 2021; https://www.pulsetoday. co.uk/news/clinical-areas/obesity-and-nutrition/new-digital-weight-management-service-opens-to-gp-referrals/ (accessed 30 Nov 2021). 